\title{
Delayed recovery from general anaesthesia following thyroidectomy: a "near miss"
}

\author{
Vihara Erangika Gunasekera Dassanayake ${ }^{1^{*}}$, Nadeeshya Dulanjalee Welikala ${ }^{2}$, Sachintha \\ Lakmal Ramasinghe ${ }^{2}$ \\ Senior Lecturer in Anaesthesiology and Consultant Anaesthetist ${ }^{l}$, Department of Surgery, Faculty of \\ Medicine, University of Colombo, Senior Registrar in Anaesthesiology ${ }^{2}$, National Hospital of Sri \\ Lanka, Sri Lanka.
}

Thyroid storm is an endocrine emergency which carries a high mortality. The spectrum of emergencies can vary from an impending storm to a thyroid crisis depending upon the degree of systemic decompensation.

It is a clinical diagnosis which can be supported by biochemical investigations. In the perioperative setting a multitude of factors can act as potential triggers for a patient to develop a thyroid storm. However subtle signs of an "impending storm" can be masked by other co-morbid factors which befits the phrase "calm before a storm".

There are a number of case reports in the literature on delayed recovery in hypothyroid patients undergoing general anaesthesia for various procedures. However, there were no reported cases of delayed recovery among patients with hyperthyroidism following surgery secondary to an impending storm.

We report a case of a 48- year old man who underwent a total thyroidectomy combined with a herniorrhaphy and a hydrocelectomy and had a delayed recovery from general anaesthesia due to an impending thyroid storm, which could have resulted in a catastrophic postoperative period.

Keywords: Impending storm; thyroid storm; thyroid crisis; delayed recovery; respiratory acidosis; hypercarbia

\section{Introduction}

Thyroid storm manifests in patients with thyrotoxicosis. The mortality rate is $1-2 \%$ in the United Kingdom. If untreated the mortality rates can be high as $100 \%$. With timely intervention, rates can be reduced to $10-50 \%$.

Burch-Wartofsky scoring system can delineate an impending storm from a thyroid crisis.

A 48-year old hyperthyroid patient with poor drug compliance presented for a total thyroidectomy, a left inguinal herniorrhaphy and hydrocelectomy. After a two and a- half hour surgery he developed respiratory acidosis,
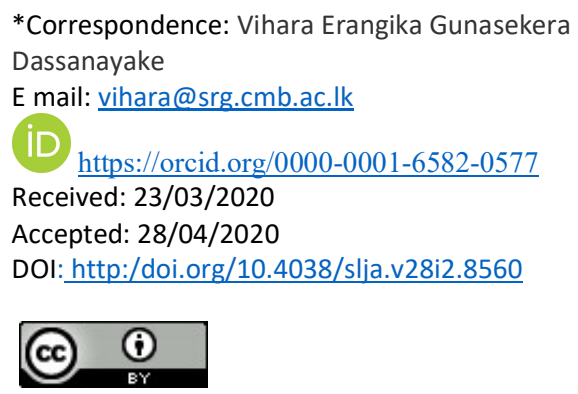

leading to a delayed recovery. Burch-Wartofsky score was 30 and he was diagnosed as an impending thyroid storm.

\section{Case presentation}

A 48-year old man weighing $62 \mathrm{~kg}$ with a height of $167 \mathrm{~cm}$ (body mass index of $22.2 \mathrm{~kg} / \mathrm{m}^{2}$ ) presented for a total thyroidectomy for a right toxic adenoma. He was investigated for a neck lump which had been increasing in size associated with hoarseness of voice. He was evaluated with a $99 \mathrm{mTc}$ thyroid scan which revealed an increased uptake in both lobes with an old nodule over the right lower pole. He had been on anti-thyroid drugs but had omitted carbimazole for one month. He was clinically euthyroid prior to surgery apart from loss of weight over the last six months. His preoperative sleeping pulse rate was $60-70$ beats per minute and blood pressure was within normal range.

He also complained of a left sided inguinal lump for two years, which was progressively increasing in size causing discomfort. On examination the lump was felt to be extending 
from the left groin to the scrotum, it was tender and irreducible. There were no signs of acute obstruction at the time of admission but there was a possibility of an impending obstruction. He was consented for a left sided herniorrhaphy, hydrocelectomy and total thyroidectomy, a combination of surgeries under general anaesthesia.

He was a diabetic for five years on metformin and gliclazide. Despite being biochemically hyperthyroid he was clinically euthyroid (Table 1). His investigations were otherwise unremarkable.

After establishing standard AAGBI monitoring, general anaesthesia was induced with $150 \mathrm{mg}$ propofol, $7.5 \mathrm{mg}$ morphine and $40 \mathrm{mg}$ atracurium. He was intubated with a size $7.5 \mathrm{~mm}$ endotracheal tube. He was ventilated with a tidal volume of $6 \mathrm{ml} / \mathrm{kg}$ of ideal body weight, a respiratory rate of 12 breaths per minute and an $\mathrm{I}: \mathrm{E}$ ratio of 1:2 with a PEEP of $5 \mathrm{cmH}_{2} \mathrm{O}$ and his end tidal carbon dioxide was $35-40 \mathrm{mmHg}$ throughout surgery.

Bilateral superficial cervical plexus blocks were performed, and diclofenac suppository was inserted. Duration of surgery was two and a half hours. He required a dose of subcutaneous soluble insulin as his intraoperative capillary blood sugar (CBS) was $260 \mathrm{mg} / \mathrm{dl}$. It reduced to $237 \mathrm{mg} / \mathrm{dl}$ at the end of surgery.

On completion of surgery, atracurium was reversed with neostigmine/atropine combination. With adequate tidal volume breathing he was extubated under deep anaesthesia. Following extubation, he remained drowsy. His blood pressure progressively increased to 200/115 $\mathrm{mmHg}$ with a pulse rate of $110-120$ beats per minute. He was sweating and rousable only to deep tactile stimulation.

CBS in the immediate post-op period was $343 \mathrm{mg} / \mathrm{dl}$. Possibility of a diabetic ketoacidosis led us to administer a further dose of soluble insulin. He was resuscitated with intravenous $0.9 \%$ normal saline. Urine for ketone bodies were negative. An arterial blood gas on $4 \mathrm{~L} /$ minute of oxygen revealed the following.

$$
\begin{aligned}
& \mathrm{PH}=7.28 \\
& \mathrm{PaCO}_{2}=51 \mathrm{mmHg} \\
& \mathrm{PaO}_{2}=141 \mathrm{mmHg} \\
& \mathrm{HCO}_{3}{ }^{-}=24 \mathrm{mmol} / \mathrm{L} \\
& \text { Base excess }=2.7 \\
& \text { Lactate }=4.3 \mathrm{mg} / \mathrm{dl}
\end{aligned}
$$

Box 1: Arterial blood gas report

He was transferred to the high dependency unit. His thyroid profile was repeated, and an endocrine referral was done. (Table1)

Table 1: Perioperative thyroid profile

\begin{tabular}{|lllll|}
\hline $\begin{array}{l}\text { Thyroid } \\
\text { profile }\end{array}$ & $\begin{array}{l}\text { Immediate } \\
\text { op }\end{array}$ & pre- & $\begin{array}{l}\text { Immediate- } \\
\text { postop }\end{array}$ & $\begin{array}{l}\text { Postop } \\
\text { day 5 }\end{array}$ \\
$\begin{array}{l}\text { Serum TSH } \\
(\mathrm{MIU} / \mathrm{L})\end{array}$ & $0.024(0.55-4.78)$ & $<0.008$ & $<0.008$ \\
$\begin{array}{l}\text { Serum } \\
(\mathrm{ng} / \mathrm{dl})\end{array}$ & $\mathrm{T} 4$ & $\begin{array}{l}2.62 \\
(0.89-1.76)\end{array}$ & 3.58 & 1.18 \\
\hline
\end{tabular}

The tachycardia and hypertension responded to two doses of intravenous labetolol. BurchWartofsky score was 30 and he was diagnosed as impending thyroid storm. He was resuscitated with intravenous fluids, hydrocortisone $100 \mathrm{mg}$ six hourly, oral carbimazole $15 \mathrm{mg}$ three times daily through a nasogastric tube and Lugols' iodine for five days. Initiation of administering propylthiouracil was delayed by four days as it was not available in the acute setting. He was prescribed oral propranolol and his blood sugar was controlled with an infusion of insulin.

Prazosin and losartan were commenced to control the blood pressure. A sudden deterioration of level of consciousness to a GCS of $9 / 15$ was noted on post op day five. CT brain was unremarkable. The reason for his low level of consciousness remained undiagnosed. His metabolic parameters were normal. In view of his low level of consciousness propylthiouracil was withheld as there was a possibility of inducing a hypothyroid state. He regained a GCS of $15 / 15$ by the seventh postoperative day. On discharge he was advised to attend the surgical clinic with a repeat thyroid profile in two weeks. 


\section{Discussion}

Thyroid storm is a medical emergency which is precipitated by a physiological insult on a background of untreated hyperthyroidism. ${ }^{1,2}$ In the initial stages with less systemic decompensation $^{1}$ an impending storm can manifest with subtle signs. If unrecognized it could result in a more severe form of decompensation resulting in thyroid storm. Though uncommon, a storm can contribute to increased mortality. $2,3,4$

Burch et al. introduced the Burch and Wartofsky point scale which assigns a numerical value based on the presence of signs and symptoms. ${ }^{5}$ An aggregate score of more than 45 implies thyroid storm and between 25-45 an impending storm. This patient's score was 30 and he was diagnosed with an impending storm on a background of hyperthyroidism as evident by his perioperative biochemical results. (Table 1)

The incidence of impending storm is not known. However, thyroid storm in the presence of thyrotoxicosis in a study conducted in Japan was 0.2 per 100,000 admissions. If untreated the mortality can be as high as $80-100 \%{ }^{6}$

There are case reports of patients presenting with an impending storm in an uncontrolled hyperthyroid state ${ }^{7}$, however no case reports were found in the literature of delayed recovery from anaesthesia secondary to respiratory acidosis as a result of an impending storm.

Hypothyroidism is a known cause of delayed recovery due to reduced metabolism of anaesthetic agents. ${ }^{8}$ This was a rare phenomenon of a delayed recovery from anaesthesia in a patient who was biochemically hyperthyroid but clinically euthyroid. Hypercarbia causing delayed recovery is rare $^{9}$ but there are case reports and we experienced this in our patient who had a near miss from developing a thyroid storm. Increased basal metabolic rate resulting in hypercarbia was the most likely cause for delayed recovery from anaesthesia.

\section{Conclusion}

A high degree of suspicion is required to diagnose an impending storm before it progresses to a lifethreatening crisis.

Marginally elevated serum thyroxine levels perioperatively should not be taken lightly despite the patient being clinically euthyroid. A background of biochemical hyperthyroidism with dual procedures resulting in a longer duration of physiological stress can be prevented with better optimization of patients' thyroid status prior to surgery.

\section{References}

1. Burch HB, Wartofsky L. Life-threatening thyrotoxicosis: thyroid storm. Endocrinology and metabolism clinics of North America. 1993;22(2):263-77

https://doi.org/10.1016/s0889-8529(18)30165-8

2. Ngo SY, Chew HC. When the storm passes unnoticed-a case series of thyroid storm. Resuscitation. 2007;73(3):485-90

https://doi.org/10.1016/j.resuscitation.2006.10.0 $\underline{03}$

3. Wilkinson JN. Thyroid storm in a polytrauma patient. Anaesthesia. 2008;63(9):1001-5

https://doi.org/10.1111/j.13652044.2008.05541.x

4. Hirvonen EA, Niskanen LK, Niskanen MM. Thyroid storm prior to induction of anaesthesia. Anaesthesia. 2004;59(10):1020-2 https://doi.org/10.1111/j.13652044.2004.03838.x

5. Salih AM, Kakamad FH, Rawezh QS, Masrur SA, Shvan HM, Hawbash MR, Lhun TH. Subacute thyroiditis causing thyrotoxic crisis; a case report with literature review. International journal of surgery case reports. 2017;33:112-4

https://doi.org/10.1016/j.ijscr.2017.02.041

6. Idrose, Alzamani Mohammad. "Acute and emergency care for thyrotoxicosis and thyroid storm." Acute medicine \& surgery vol. 2,3 147157. 12 May. 2015.

https://doi.org/10.1002/ams2.104

7. Ma Y, Li H, Liu J, Lin X, Liu H. Impending thyroid storm in a pregnant woman with undiagnosed hyperthyroidism: A case report and literature review. Medicine (Baltimore). 2018;97(3): e9606.

https://doi.org/10.1097/md.0000000000009606

8. Kumar VV, Kaimar P. Subclinical hypothyroidism: A cause for delayed recovery from anaesthesia? Indian journal of anaesthesia. 2011;55(4):433-4 https://doi.org/10.4103/0019-5049.84836

9. K. Kerr, G. H. Mills, Intra-operative and postoperative hypercapnia leading to delayed respiratory failure associated with transanal endoscopic microsurgery under general anaesthesia, BJA: British Journal of Anaesthesia 2001;86(4):586-589 https://doi.org/10.1093/bja/86.4.586 